\title{
O ensino das funções trigonométricas através da resolução de problemas com o uso do geogebra
}

\author{
Teaching trigonometric functions through troubleshooting \\ with the use of geogebra
}

\section{Enseñanza de funciones trigonométricas mediante la resolución de problemas con el uso de geogebra}

Felipe de Almeida Costa Doutorando em Ensino de Ciências e Matemática, Universidade Cruzeiro do Sul UNICSUL

São Paulo, São Paulo, Brasil E-mail: felipeacosta@prof.educacao.sp.gov.br

Orcid: 0000-0002-9055-9427

Norma Suely Gomes Allevato Professora do Programa de Ensino de Ciências e Matemática, Universidade Cruzeiro do Sul - UNICSUL São Paulo, São Paulo, Brasil E-mail: normallev@gmail.com Orcid: 0000-0001-6892-606X

Resumo: Esse artigo trata de uma ação realizada em uma turma de segundo ano do Ensino Médio, em que o primeiro autor é professor. Aqui traremos uma aplicação do GeoGebra que foi disponibilizada para a turma com o objetivo de que eles, alunos, iniciassem o estudo de funções trigonométricas. Nessa ação utilizou-se um problema gerador e ao manusear a aplicação e a partir de seus conhecimentos prévios os alunos discutiam as possíveis soluções para os problemas, que os levavam a construir o novo conhecimento "funções trigonométricas". Este trabalho é de cunho qualitativo e para a Resolução de Problemas utilizamos como referencial as proposições de Onuchic e Allevato (2014). Concluímos que o trabalho com a Resolução de Problemas e o GeoGebra foram facilitadores para a aprendizagem de um novo conceito por parte dos alunos desse estudo e que um problema gerador pode constituir-se a partir das próprias inquietações dos alunos acerca do conteúdo.

Palavras-chave: Educação Matemática, Funções Trigonométricas, Resolução de Problemas e GeoGebra. 
Abstract: This article deals with an action carried out in a class of second year of high school, in which the first author is a teacher. Here we will bring an application of GeoGebra that was made available to the class with the objective that they, students, start the study of trigonometric functions. In this action a generating problem was used and when handling the application and from their previous knowledge the students discussed the possible solutions to the problems, which led them to build the new knowledge "trigonometric functions". This work is of a qualitative nature and for the Resolution of Problems we use As a reference the propositions of Onuchic and Allevato (2014). We conclude that the work with Problem Solving and GeoGebra were facilitators for the learning of a new concept by the students of this study and that a generating problem can be constituted from the students' own concerns about the content.

Keywords: Mathematics Education, Trigonometric Functions, Problem Solving and GeoGebra..

Resumen: Este artículo trata de una acción realizada en una clase de segundo año de bachillerato, en la que el primer autor es profesor. Aquí traeremos una aplicación de GeoGebra que se puso a disposición de la clase con el objetivo de que ellos, los alumnos, inicien el estudio de las funciones trigonométricas. En esta acción se utilizó un problema generador y al manejar la aplicación y a partir de sus conocimientos previos los estudiantes discutieron las posibles soluciones a los problemas, lo que los llevó a construir los nuevos conocimientos "funciones trigonométricas". Este trabajo es de carácter cualitativo y para la Resolución de Problemas utilizamos como referencia las proposiciones de Onuchic y Allevato (2014). Concluimos que el trabajo con Solución de Problemas y GeoGebra fueron facilitadores para el aprendizaje de un nuevo concepto por parte de los estudiantes de este estudio y que se puede constituir un problema generador a partir de las propias inquietudes de los estudiantes sobre el contenido.

Palabras clave: Educación Matemática, Funciones Trigonométricas, Resolución de Problemas y GeoGebra.

Recebido em 26/04/2021

Aceito em

$14 / 08 / 2021$ 


\section{INTRODUÇÃO}

Este trabalho apresenta uma ação realizada em uma escola pública, em que o professor titular da turma, que é primeiro autor deste artigo, quis apresentar o conceito de função trigonométrica a partir de um problema; para essa ação utilizou-se dos pressupostos metodológicos da Resolução de Problemas presentes em Allevato e Onuchic (2014).

Outro motivo para a realização desta pesquisa foi o fato de entendermos que muitas publicações com a Resolução de Problemas ancoradas nas dez etapas sugeridas para a Metodologia de Ensino-Aprendizagem-Avaliação de Matemática através da Resolução de Problemas de Allevato e Onuchic (2014), não apresentavam o "passo a passo" para o desenvolvimento dessa forma de trabalho para a sala de aula. Visualizamos esse fato em um curso de formação de professores, em que estudávamos diversos trabalhos com a abordagem mencionada e muitos professores evidenciavam que precisavam de mais subsídios para colocar em prática essa metodologia. Assim, percebemos que seria importante produzir um trabalho exemplificando e destacando mais esses elementos/etapas, pois ele poderia ajudar o professor, e não só os pesquisadores, no caminho para utilizar a MEAAMRP em suas aulas.

Como informado anteriormente, este trabalho foi realizado em uma escola pública da região periférica do estado de São Paulo, com alunos de uma turma do $2^{\circ}$ ano do Ensino Médio - EM que iriam iniciar o estudo de funções trigonométricas. Para a realização da pesquisa utilizamos a Resolução de Problemas e apoiamo-nos em ferramentas tecnológicas, no caso o aplicativo GeoGebra para celular.

Este trabalho foi dividido em seis seções, incluindo esta introdução. Na próxima seção, refletimos sobre a importância do ensino das funções trigonométricas e o uso das TICs, visto que utilizaremos o apoio do celular para o ensino. Na terceira seção, apresentamos o aporte teórico da Resolução de Problemas, fundamentamos nosso 


\section{Universidade Federal da Grande Dourados}

estudo, principalmente, nas ideias de Allevato e Onuchic (2014). Na quarta seção enunciamos a metodologia de pesquisa utilizada. A seguinte, quinta seção, apresenta como se deu o caminho da pesquisa, apresentando e analisando os dados. E, finalmente, a última seção registra as considerações finais e caminhos futuros para esse estudo.

\section{FUnÇÕES TRIGONOMÉTRICAS E TECNOLOGIAS DIGITAIS}

(O corpo do texto deve estar em Liberation Sans, tamanho 12). Parte principal do artigo, que contém a exposição ordenada e pormenorizada do assunto tratado. Dividese em seções e subseções. Esse periódico utiliza para citações e referências as normas da American Psychological Association (APA).

De acordo com o estilo APA, as citações com menos de 40 palavras devem permanecer incorporadas no texto, entre aspas duplas. Exemplo: Concluem que o estudo realizado permitiria suportar que "os teóricos críticos, às vezes, têm programa de trabalho político claro, focado nos interesses de grupos específicos identificáveis" (Alvesson \& Deetz, 1998, p. 237).

A partir da nossa prática, percebemos que os alunos possuem algumas dificuldades para assimilar os conceitos de funções trigonométricas; nesse sentido, entendemos que devemos utilizar diferentes abordagens para o ensino desse tipo de função. Nessa perspectiva, o GeoGebra e a Resolução de Problemas são opções que podem ser consideradas quando trabalhamos com o ensino dessas funções.

Em relação ao ensino de trigonometria os Parâmetros Curriculares Nacionais de Matemática-PCN já explicitavam que o trabalho com trigonometria deve ser realizado:

[...] evitando-se o investimento excessivo no cálculo algébrico das identidades e equações para enfatizar os aspectos importantes das funções trigonométricas e da análise de seus gráficos. Especialmente para o indivíduo que não prosseguirá seus estudos nas carreiras ditas exatas, o que deve ser assegurado são as aplicações da Trigonometria na resolução de problemas que envolvam medições, em especial o cálculo de distâncias inacessíveis, e na construção de modelos que correspondam a fenômenos periódicos. Nesse sentido, um projeto 
envolvendo também a Física pode ser de grande oportunidade de aprendizagem significativa (Brasil, 2000, p.44).

E Esta indicação dos PCN ressalta a importância de os alunos terem contato com as funções trigonométricas, em especial, compreenderem seus gráficos e estabelecerem relações com as diversas áreas do conhecimento buscando identificar os fenômenos periódicos presentes na natureza.

Mais recentemente, também a Base Nacional Comum Curricular - BNCC, apresenta indicações em relação à trigonometria, e menciona a importância de:

Identificar as características fundamentais das funções seno e cosseno (periodicidade, domínio, imagem), por meio da comparação das representações em ciclos trigonométricos e em planos cartesianos, com ou sem apoio de tecnologias digitais (Brasil, 2017, p. 105).

A BNCC acrescenta que para o estudo das funções trigonométricas podem ser utilizadas as tecnologias digitais. Elas constituem apoio relevante, por exemplo, para fazer comparações entre os ciclos, que são necessárias à compreensão da periodicidade, do domínio e da imagem desse tipo de função.

A BNCC traz 8 (oito) competências específicas para a aprendizagem de Matemática e em uma delas é explicitado o uso de tecnologias; assim, entendemos que as tecnologias devem ser consideradas para o ensino de Matemática, concordando que podem ser ferramentas eficientes para o ensino e a aprendizagem e portanto devem ser utilizadas. A quinta competência da BNCC refere-se a:

Utilizar processos e ferramentas matemáticas, inclusive tecnologias digitais disponíveis, para modelar e resolver problemas cotidianos, sociais e de outras áreas de conhecimento, validando estratégias e resultados (Brasil, 2018, p. 267).

Nesse sentido, Costa (2017) utilizou o GeoGebra para o ensino das funções trigonométricas e aponta, em sua pesquisa, que essa ferramenta facilitou a aprendizagem dos alunos, pois eles conseguiam fazer diversas simulações enquanto resolviam as atividades propostas. 


\section{Universidade Federal da Grande Dourados}

Em um trabalho semelhante ao de Costa (2017), Meneghelli (2018) produziu, a partir de sua pesquisa, um produto educacional com atividades norteadas pela MEAAMRP e mediadas pelo software GeoGebra. Nesse produto, a autora buscou proporcionar a compreensão das relações entre as funções seno e cosseno a partir de atividades subsidiadas pelas orientações dos documentos oficiais e recursos metodológicos bastante atuais.

Este trabalho difere dos dois anteriores, pois utiliza a Resolução de Problemas como estratégia de ensino e a aplicação do GeoGebra é um dos instrumentos utilizados pelos alunos para buscar as possíveis soluções para o problema gerador, o problema que irá desencadear o ensino-aprendizagem do novo conhecimento.

\section{Resolução de Problemas}

O ensino-aprendizagem-avaliação de Matemática através da RP é uma metodologia de ensino em que, a partir de um problema gerador, alunos e professores, juntos, buscam aprender conceitos, processos, generalizações e técnicas que envolvem a Matemática. Mais do que isso, essa forma de trabalho com a Resolução de Problemas promove um ensino em que o aluno é o protagonista do seu aprendizado, ou seja, ele busca a(s) solução(ões) de um problema e para isso utiliza o seu repertório matemático de modo que a resolução desse problema o leva à construção ou reconstrução das ideias, conceitos e conteúdos matemáticos.

Nessa perspectiva, Allevato e Onuchic (2011) sugerem que um bom problema deve ser desafiador e que sua resolução não deve ser conhecida a priori ou memorizada previamente pelos alunos, assim:

O aluno analisa seus próprios métodos e soluções obtidas para os problemas, visando sempre à construção do conhecimento. Essa forma de trabalho do aluno é consequência do seu pensar matemático, levando-o a elaborar justificativas e dar sentido ao que faz. De outro lado, o professor avalia o que está acontecendo e os resultados do processo, com vistas a reorientar as práticas de sala de aula, quando necessário (Allevato; Onuchic, 2011, p. 81). 
Buscando realizar um trabalho através da Resolução de Problemas, Allevato e Onuchic (2014) sugerem dez etapas para o desenvolvimento dessa metodologia, sintetizadas na figura a seguir:

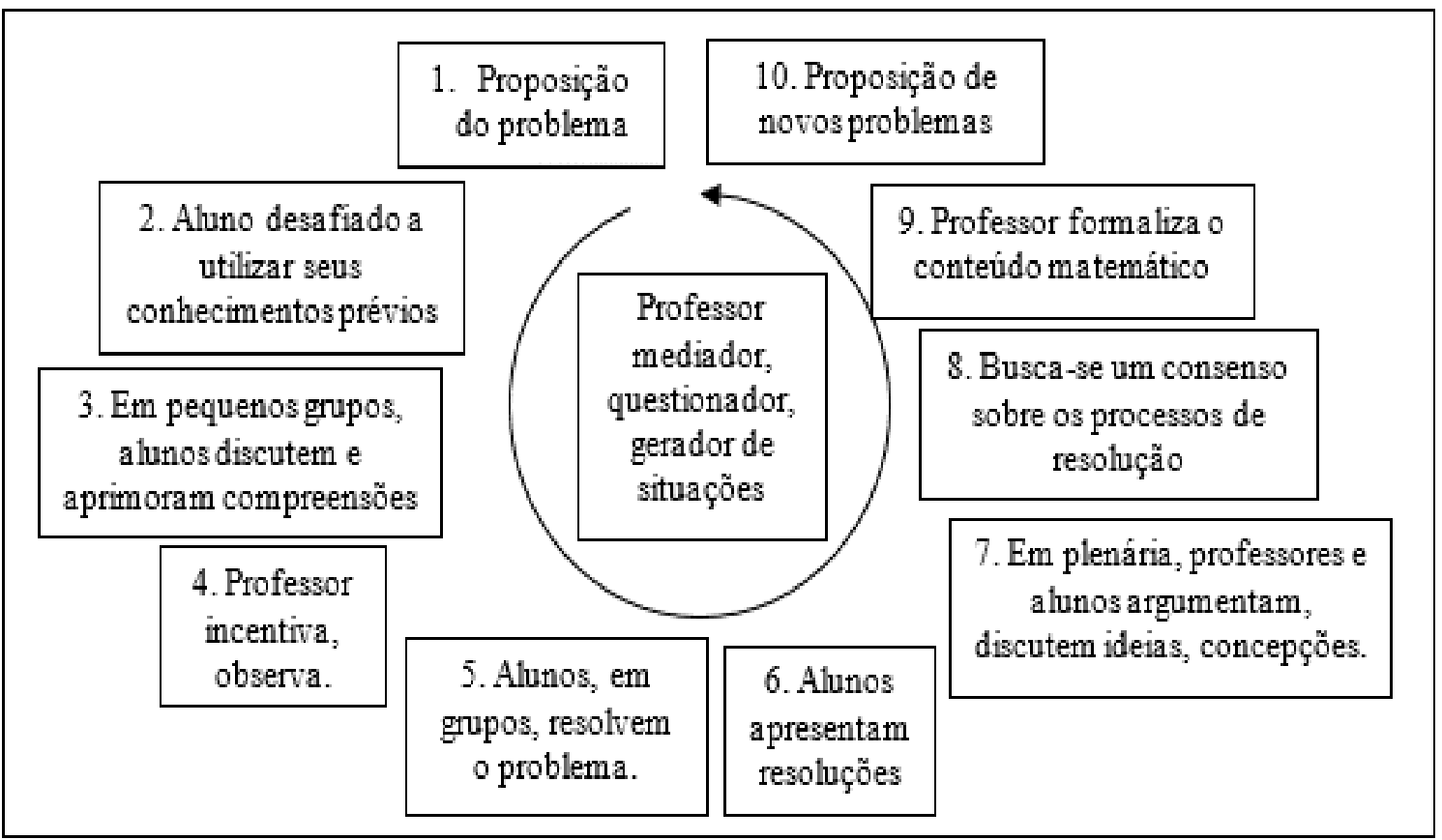

Figura 1. Etapas propostas para a resolução de problemas. Fonte: Allevato, 2014.

Assim como as autoras, entendemos que a Resolução de Problemas não precisa ser um fim, mas um meio para aprender Matemática. Gonçalves e Allevato (2020) utilizou essas dez etapas para o trabalho com Resolução de Problemas em sua pesquisa sobre as funções definidas por várias sentenças, e concluiu que o ensino e aprendizagem através da Resolução de Problemas favoreceu a aprendizagem significativa, bem como potencializou a investigação matemática, a criatividade e o trabalho colaborativo, que possibilitou uma notória evolução na compreensão dos conceitos e conteúdos matemáticos. 
Encontramos na BNCC indicadores de que não devemos apenas utilizar a Resolução de Problemas para ensinar Matemática, como também ensinar o que é Resolução de Problemas. A BNCC destaca o seguinte:

O aluno analisa seus próprios métodos e soluções obtidas para os problemas, visando sempre à construção do conhecimento. Essa forma de trabalho do aluno é consequência do seu pensar matemático, levando-o a elaborar justificativas e dar sentido ao que faz. De outro lado, o professor avalia o que está acontecendo e os resultados do processo, com vistas a reorientar as práticas de sala de aula, quando necessário (Allevato; Onuchic, 2011, p. 81).

Deste modo, entendemos que um trabalho com tecnologias digitais e Resolução de Problemas pode potencializar o ensino e a aprendizagem de conceitos matemáticos, em especial das funções trigonométricas, favorecendo a investigação matemática e o interesse dos alunos, que podem utilizar o celular como ferramenta pedagógica em sala de aula.

\section{Metodologia}

O Esta pesquisa é de abordagem qualitativa, ou seja, buscamos interpretar o fenômeno pesquisado observando-o com profundidade, no sentido de analisar o processo como um todo. Goldenberg (2007) entende que essa abordagem não se preocupa com a implantação de leis para a pesquisa, mas com a compreensão aprofundada dos dados investigados.

Para a obtenção dos dados utilizamos a observação participante, realizada enquanto os alunos eram envolvidos em processos de resolução de problemas em aula. Nesse modelo de investigação, o pesquisador se insere no ambiente pesquisado buscando as ações mais fidedignas que aparecem no contexto da pesquisa. Para Vianna (2007), a observação participante: i) possibilita a entrada a determinados acontecimentos que seriam privativos e aos quais um observador estranho não teria acesso; e ii) permite a observação não apenas de comportamentos, mas também de atitudes, opiniões, sentimentos, além de superar a problemática do efeito observador.

E Lüdke e André (1986, p. 28) ressaltam que a observação participante "é uma estratégia que envolve, pois, não só a observação direta, mas todo o conjunto de 


\section{Universidade Federal da Grande Dourados}

técnicas metodológicas pressupondo um grande envolvimento do pesquisador na situação estudada".

Os registros das observações foram feitos com o auxílio de um diário de campo, instrumento em que o observador registra as ações observadas quando se insere no meio pesquisado. Esse instrumento pode ser compreendido como:

um dos instrumentos mais ricos de coleta de informações durante o trabalho de campo. É nele que o pesquisador registra observações de fenômenos, faz descrições de pessoas, cenários e episódios, e até transcrições de alguns diálogos. Quanto mais próximo do momento da observação for feito o registro, maior será a acuidade da informação (Fiorentini e Lorenzato, 2012, p. 118-119).

Na pesquisa também utilizamos a análise documental, buscando relacionar os dados obtidos com a teoria utilizada. Lüdke e André (1986, p. 38) consideram que "a análise documental pode se constituir em uma técnica valiosa de abordagem de dados qualitativos, seja complementando as informações obtidas por outras técnicas, seja desvelando aspectos novos de um tema ou problema". Os documentos analisados foram a soluções apresentadas pelos alunos no caderno e/ou celular e as produções realizadas pelo professor e alunos no quadro.

\section{Caminhos da Pesquisa}

Este estudo surgiu a partir de dois pontos fundamentais: o primeiro deles referese a tentar apresentar mais minuciosamente as dez etapas da MEAAMRP e evidenciar como os professores da Educação Básica poderiam realizar essa metodologia em suas aulas. Esse propósito decorre de um fato que foi evidenciado em um curso de formação de professores conduzido pelo primeiro autor deste trabalho. Ao estudarmos diversos artigos percebíamos a intencionalidade, dados e conclusões dos pesquisadores, porém os professores presentes na formação não compreendiam bem todas as etapas que thes eram apresentadas nos textos analisados. Eles entendiam que os pesquisadores atingiram seus objetivos com as pesquisas relatadas, porém não estavam tão evidentes as etapas no processo da RP, e para os professores que estão iniciando essa dinâmica é fundamental apresentar 


\section{Universidade Federal da Grande Dourados}

cada etapa da MEAAMRP. Desse modo, esta seção tem como objetivo apresentar cada uma das etapas proposta por Allevato e Onuchic (2014).

O segundo ponto surgiu em uma aula com alunos do EM antes da apresentação do novo conceito, funções trigonométricas, quando um aluno fez o seguinte questionamento: Qual é o seno de 135? Isso aconteceu pois o professor enviou anteriormente uma lista de exercícios para a resolução dos alunos e em um desses exercícios, apresentava um triangulo, no qual um dos ângulos apresentava essa medida; os alunos, até aquela aula, tinham trabalhado apenas com ângulos notáveis. Porém, a partir daquela questão o professor percebeu a oportunidade de abordar o conceito de funções trigonométricas através da Resolução de Problemas e utilizou o questionamento do aluno como o problema gerador, ou seja, o problema que iria desencadear o novo conhecimento. A seguir apresentamos todas as etapas da MEAAMRP.

\section{Etapa1- Proposição do Problema}

Nessa etapa deve ocorrer a escolha do problema; ele deve ser capaz de mobilizar os alunos na busca de sua solução. Allevato e Onuchic (2014) dizem que o "problema é tudo aquilo que não se sabe fazer, mas que se está interessado em resolver". No caso de ser um problema gerador, deve ser proposto de modo que auxilie a construção de um novo conhecimento. Nesse sentido, entendemos que escolher o problema, geralmente, é uma tarefa do professor, porém se ele partir do aluno, o professor deve pensar se esse problema será capaz de auxiliar na construção do novo conhecimento. No caso do nosso trabalho, o problema partiu de um questionamento dos alunos e percebemos seu potencial para a construção do novo conhecimento. As 


\section{Universidade Federal da Grande Dourados}

Figuras 2 e 3 apresentam, respectivamente, o exercício que desencadeou o problema e o problema gerador.

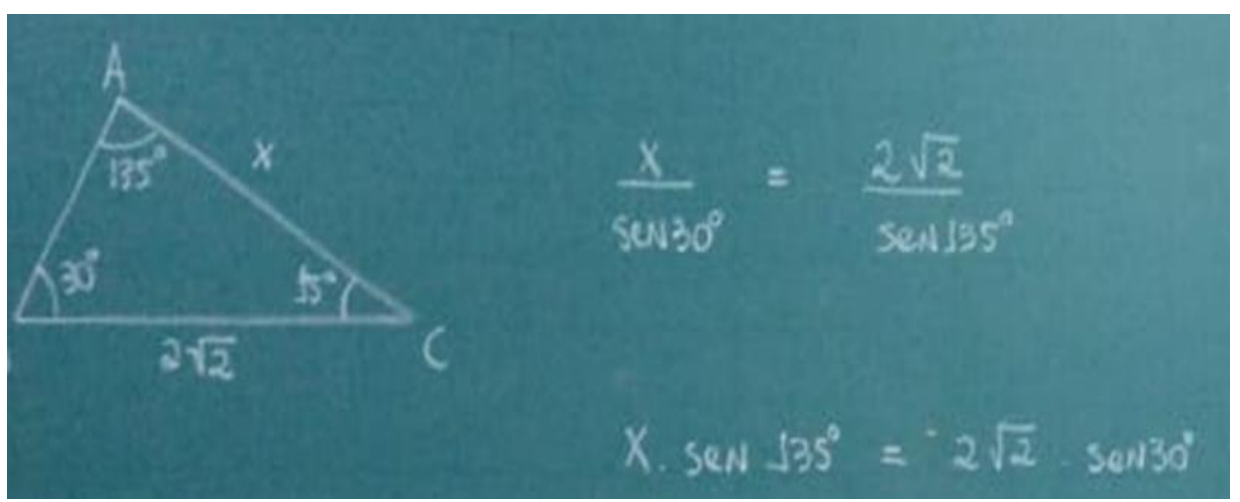

Figura 2. Exercício que desencadeou o Problema.

Fonte: Dados da pesquisa.

Vale esclarecer que esse exercício foi proposto ao fim do estudo de lei dos senos e dos cossenos, porém, até ali, todos os exercícios utilizavam ângulos notáveis; assim ao perceber a necessidade de saber qual o valor do seno de 135으, surgiu o questionamento do aluno.

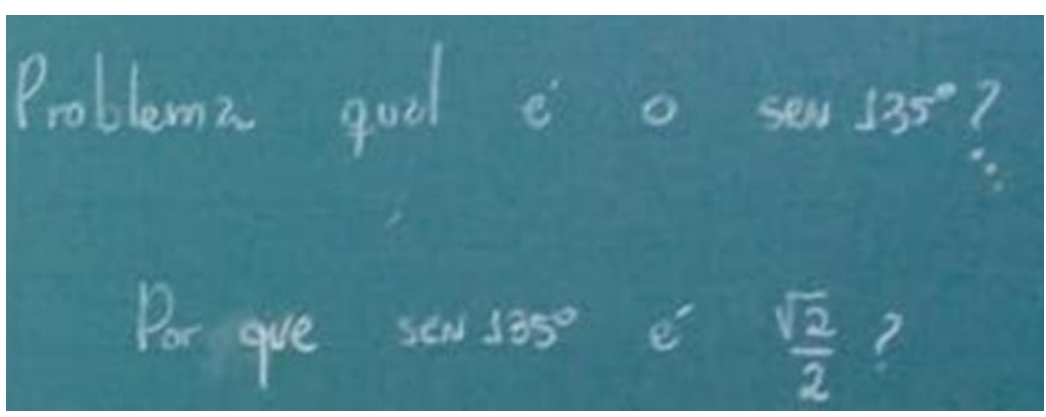

Figura 3. Problema gerador, proposto pelo aluno e professor.

Fonte: Dados da pesquisa.

Percebendo que muitos alunos conheciam o valor do seno de 135으, o professor alterou o problema, pois, mais que saber o valor, é importante entender o porquê desse valor; e como os alunos ainda não tinham feito o estudo de funções trigonométricas, se fez importante realizar esse questionamento. Allevato e Onuchic 


\section{Universidade Federal da Grande Dourados}

(2011) consideram que problemas devem ser dados de modo a engajar os alunos no "pensar sobre" e no desenvolvimento da Matemática importante que eles precisam aprender.

Etapa 2- Alunos desafiados a utilizar seus conhecimentos prévios:

Aqui os alunos devem colocar seus conhecimentos prévios em jogo e, para isso, o professor pode auxiliar com questionamentos fazendo com que pensem possibilidades para solucionar o problema. Para auxiliar nesse processo, ajudamos os alunos a relembrar os valores do seno e do cosseno para os ângulos notáveis, o ciclo trigonométrico, e recorremos ao app GeoGebra para celular (Figuras 4, 5 e 6).

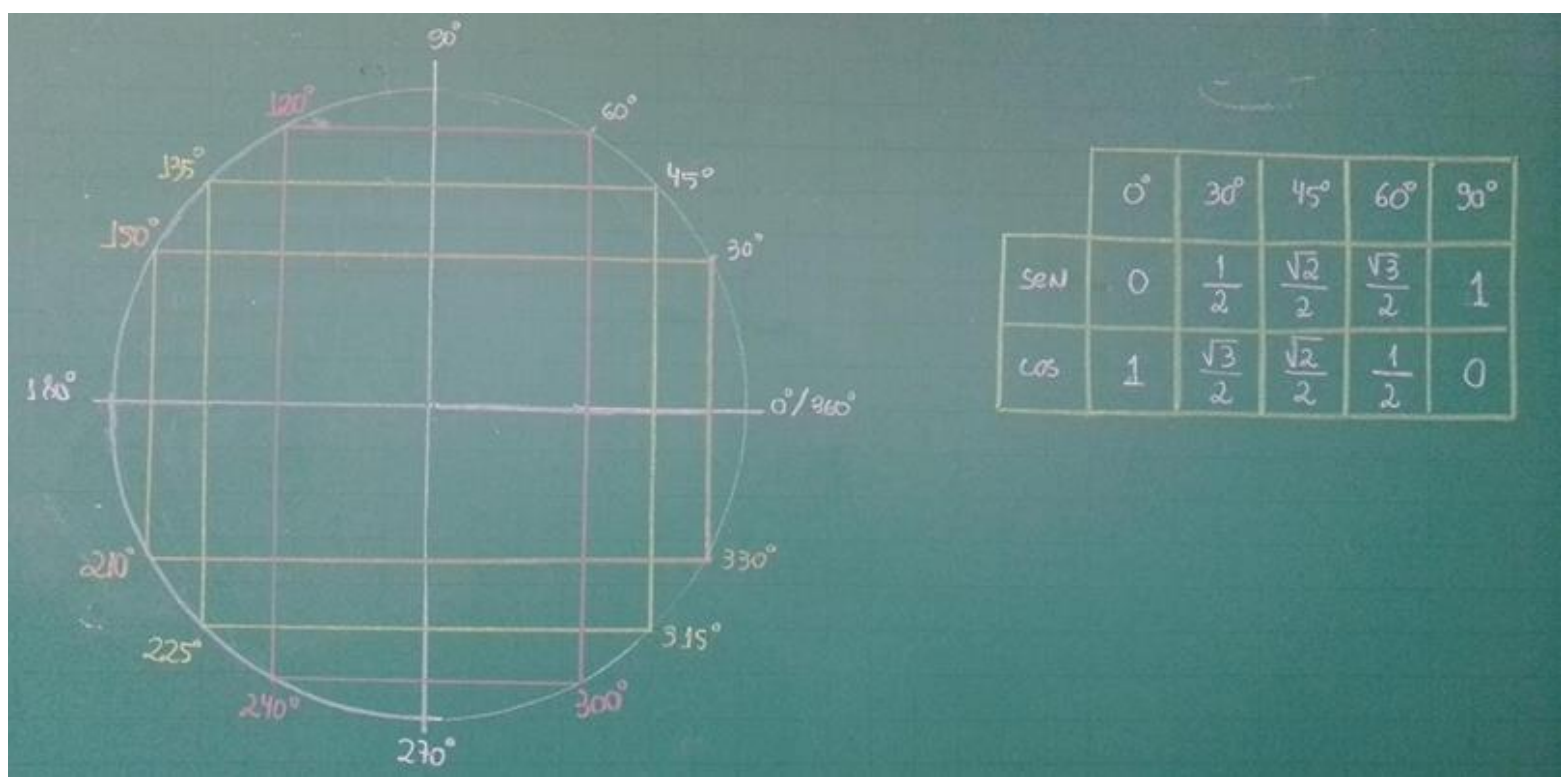

Figura 4. Ciclo trigonométrico e ângulos notáveis.

Fonte: dados da pesquisa.

Como descrito anteriormente o professor buscou conhecimentos que os alunos já tinham e introduziu o ciclo trigonométrico com os ângulos já trabalhados. Em seguida, usando o GeoGebra, o professor auxiliou os alunos a construir o ciclo trigonométrico no celular de modo que pudessem perceber as regularidades presentes no ciclo, quando utilizavam a construção/aplicação desenvolvida pelo professor.

A Figura 5 mostra como ficou a aplicação construída no app: 


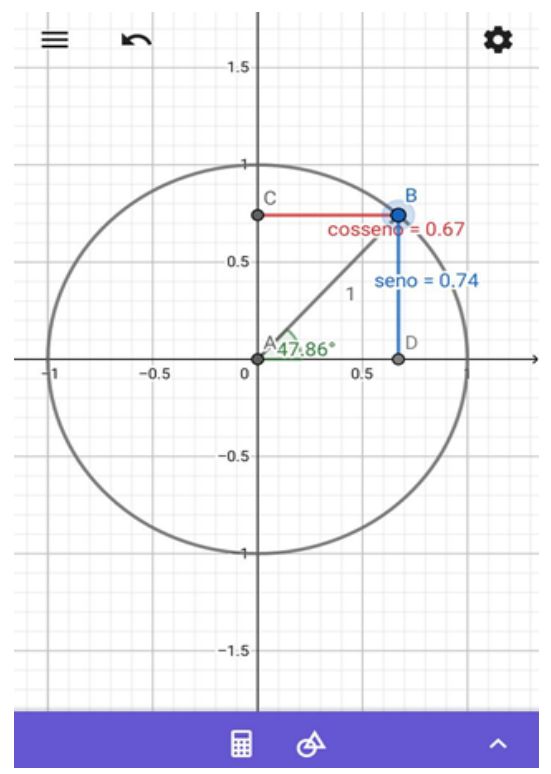

Figura 5. Ciclo trigonométrico construído no GeoGebra do celular.

Fonte: Dados da pesquisa.

O GeoGebra tornou-se importante, pois nele era possível manipular os ângulos e verificar diversos valores de "seno e cosseno" no ciclo, assim o aplicativo era um meio para o conhecimento e não um fim.

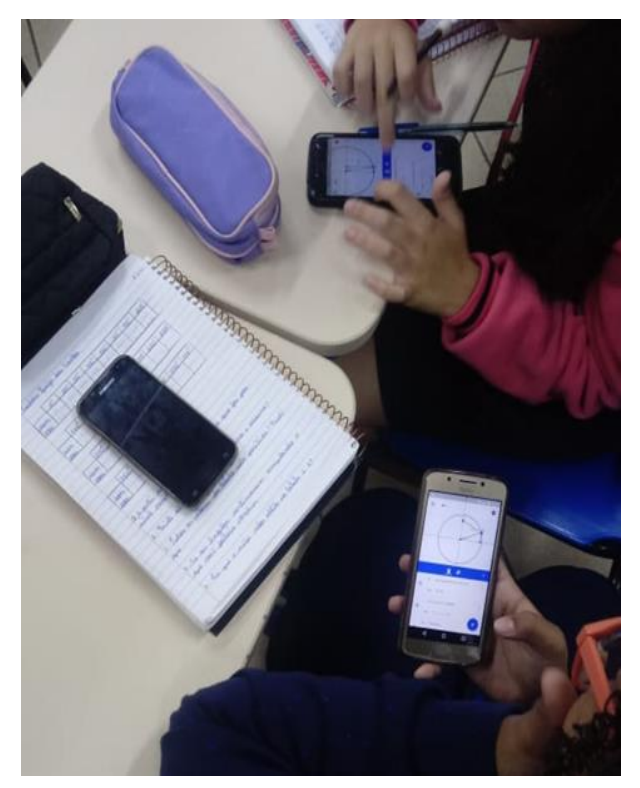

Figura 6. Ciclo trigonométrico sendo manipulado pelos alunos no GeoGebra. Fonte: Dados da pesquisa. 


\section{Universidade Federal da Grande Dourados}

Com a utilização do GeoGebra percebemos que os alunos ficaram mais motivados na busca por valores de senos e cossenos de outros ângulos. $E$ percebemos que o software e o processo da resolução de problemas desencadearam aspectos positivos, conforme mencionado por Serrazina (2017, p.57):

na resolução de problemas inserida num ambiente propício e favorável, o aluno verifica a validade dos conceitos matemáticos, realiza conjecturas, relaciona os conceitos, generaliza, utiliza os procedimentos num contexto significativo, tem uma atitude reflexiva e desenvolve a capacidade de raciocínio e o pensamento matemático.

O GeoGebra auxiliou no processo de reflexão e na elaboração de generalizações, pois ao utilizar a aplicação eles validavam ou ressignificavam ideias preexistentes.

Etapas 3, 4 e 5 - Em pequenos grupos, alunos discutem e aprimoram compreensões; o professor incentiva e observa; os alunos, em grupos, resolvem o problema:

Entendemos que essas etapas se desenvolvem em conjunto. No trabalho através da Resolução de Problemas, compreendemos que a busca pela solução do problema envolve três aspectos mencionados por Van de Walle (2009), ao destacar que um problema voltado para a aprendizagem matemática deve possuir algumas características: (i) ele deve começar onde os estudantes estão, ou seja, deve ser desafiador e interessante e fazer sentido para o estudante; (ii) o aspecto problemático ou envolvente do problema deve estar relacionado à Matemática que os alunos vão aprender; logo, o foco principal é a compreensão das ideias matemáticas, e não o contexto dos problemas e/ou a atividade não matemática; (iii) a aprendizagem matemática nele envolvida requer justificativas e explicações para as respostas e os métodos, pois os alunos precisam compreender que é deles a responsabilidade de determinar e justificar se as respostas estão corretas.

Nesse sentido, essas etapas devem garantir que a aprendizagem através da Resolução de Problemas aconteça. Nessa metodologia, é entendido que o conhecimento deve ser partilhado, sendo necessário o trabalho em grupo, pois assim como Sanches (2005, p. 144), entendemos que quando vários sujeitos dependem uns 
dos outros para o sucesso final, todos se esforçam para um bom desempenho, promovendo a cooperação e a colaboração, aplicando a máxima "não se pode ter sucesso sem os outros". E, além disso, os estudantes compartilham seus conhecimentos potencializando o ensino e a aprendizagem.

Porém todo esse processo depende da ação do professor que deve mediar para que o processo de ensino-aprendizagem aconteça. Serrazina (2017, p. 66) esclarece que:

Aos professores é atribuído o papel de levar os alunos a ler e compreender os problemas apresentados na forma escrita, a ouvir e compreender os problemas apresentados oralmente e a ler e dialogar sobre os problemas numa diversidade de formas e meios.

Além disso, na ação de ensinar através da Resolução de Problemas o professor pode apresentar novos problemas, que Allevato e Onuchic denominam problemas parciais ou secundários, para manter e engajar os alunos na busca pela solução do problema gerador. Nas Figuras 7 e 8, apresentamos os problemas segundários propostos pelo professor para que os alunos, em grupos, continuassem engajados no processo de discussão e aprendizagem.

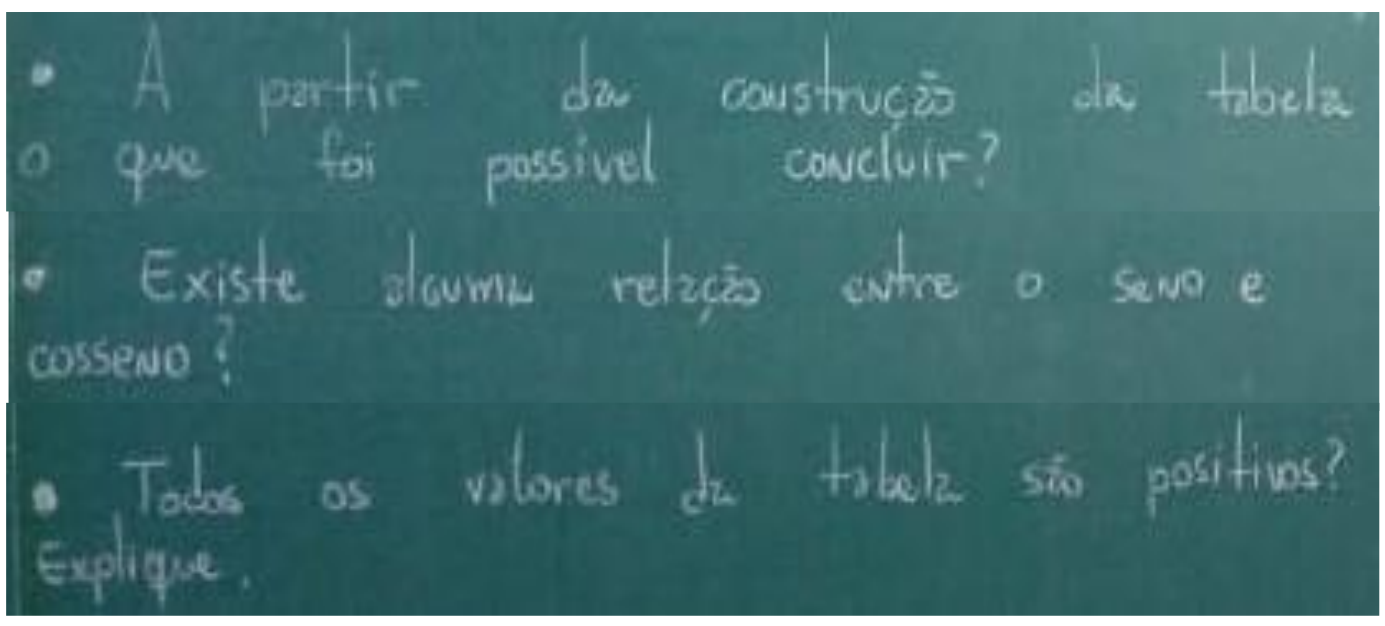

Figura 7. Questões secundárias apresentadas pelo professor.

Fonte: Dados da Pesquisa. 


\section{Universidade Federal da Grande Dourados}

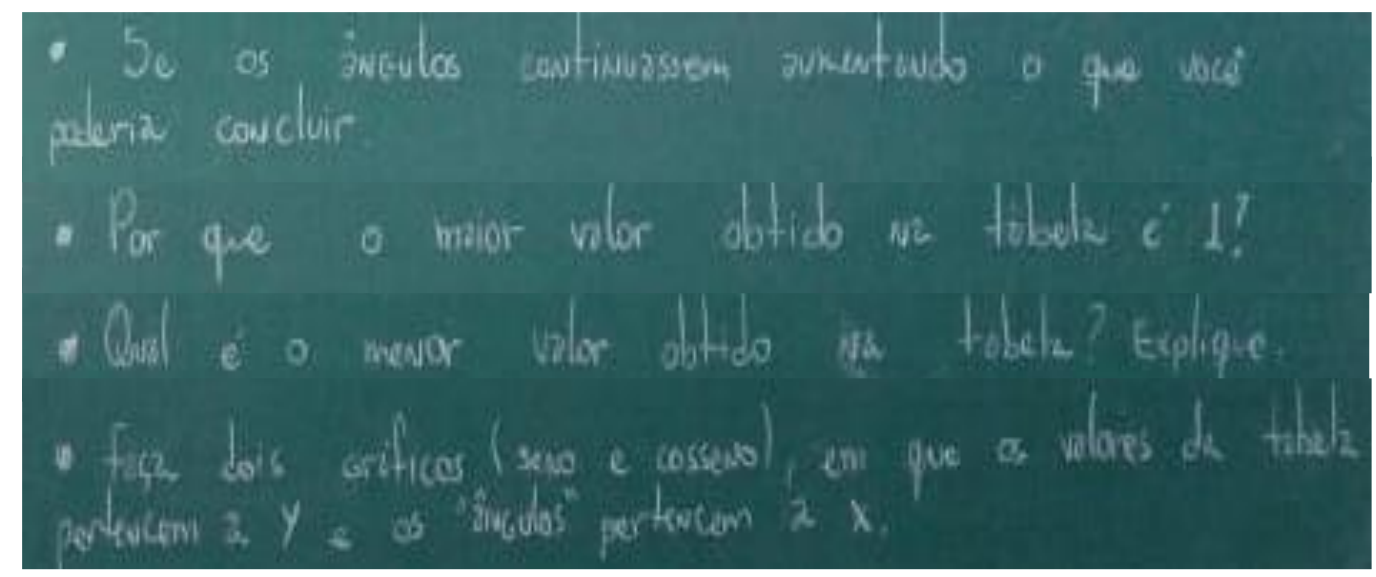

Figura 8. Questões secundárias apresentadas pelo professor.

Fonte: Dados da Pesquisa.

As questões surgiram quando o professor propôs aos alunos que criassem uma tabela com os valores que encontraram na aplicação do GeoGebra, no caso; ele orientou que os alunos construíssem uma tabela como valores de 15 em 15 graus até o $360^{\circ}$, conforme Figuras 9 e 10.

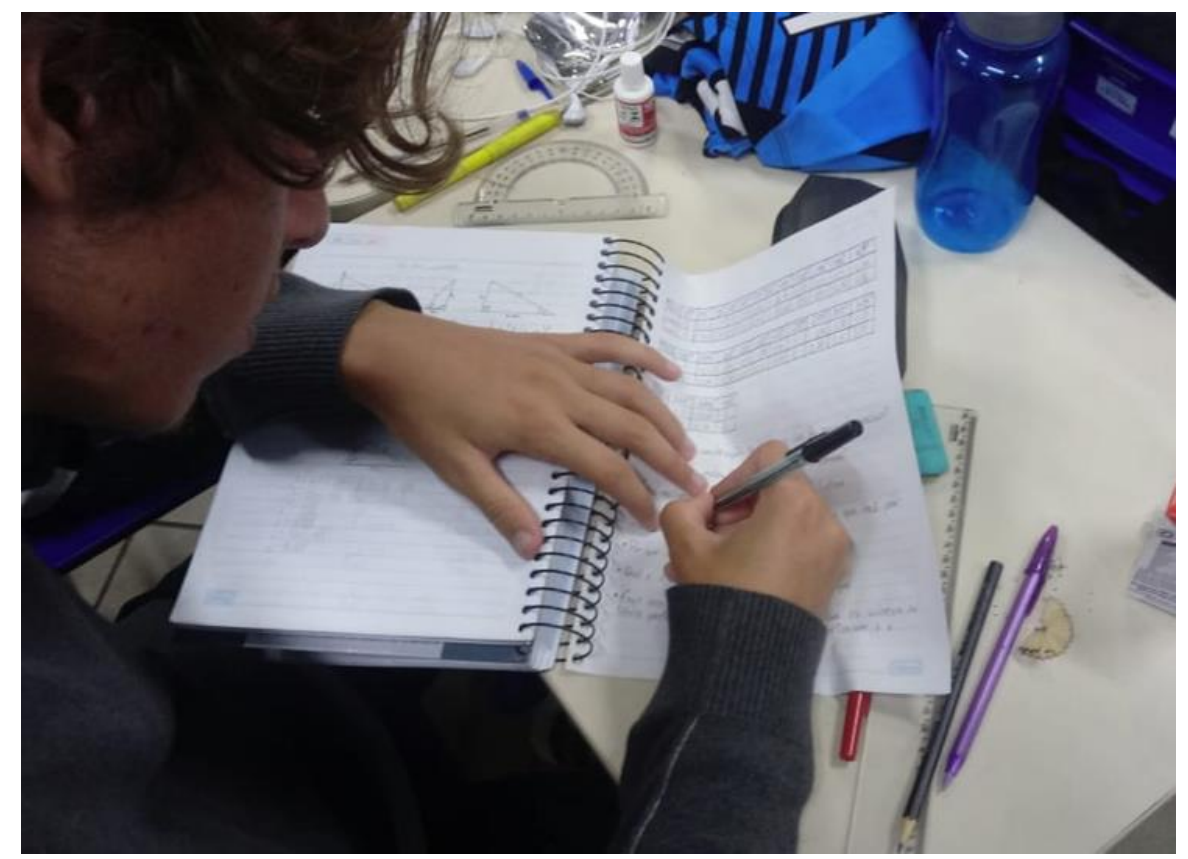

Figura 9. Alunos construindo a tabela e desenvolvendo as resoluções Fonte: Dados da Pesquisa. 


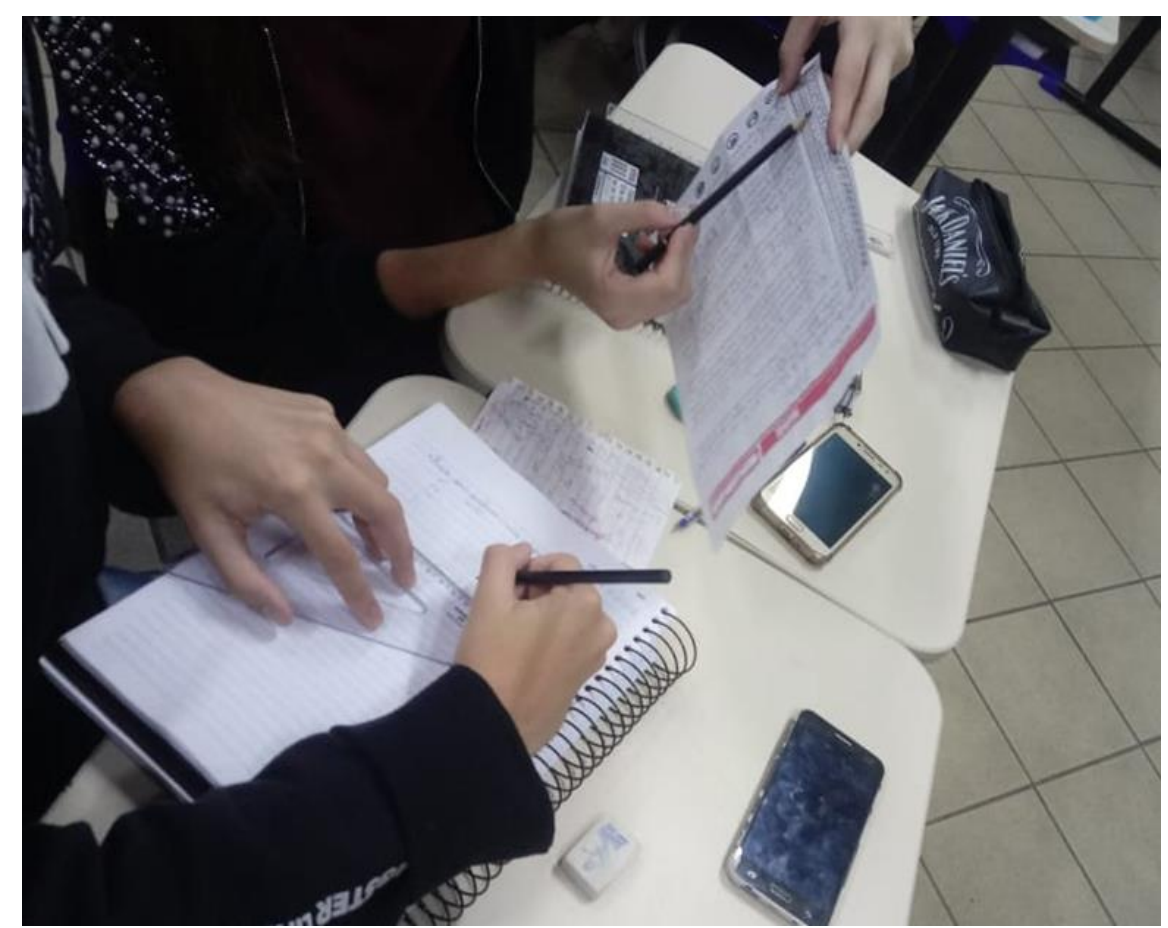

Figura 10. Alunos construindo a tabela e desenvolvendo as resoluções.

Fonte: Dados da Pesquisa.

Durante todo o trabalho, o professor incentivava os alunos na busca de soluções e, principalmente, pedia para que os alunos, nos grupos, discutissem e compartilhassem suas ideias.

Etapa 6 - Alunos apresentam suas soluções;

Nesta etapa o professor tenta garantir que os alunos apresentem suas soluções e, caso seja possível, que eles demonstrem os seu pensamento. Em nosso trabalho, a maior parte dos alunos apresentou as ideias sem a necessidade de ir ao quadro; porém, um dos grupos quis apresentar seus pensamentos para toda a turma (Figura 11) - no caso, ele queria explicar que as projeçoes de seno e cosseno, dependendo do quadrante podem ter valores positivos ou negativos. ( $O$ corpo do texto deve estar em Liberation Sans, tamanho 12). Parte inicial do artigo na qual devem constar a delimitação do assunto tratado, os objetivos da pesquisa e outros elementos necessários para situar o tema do artigo. 


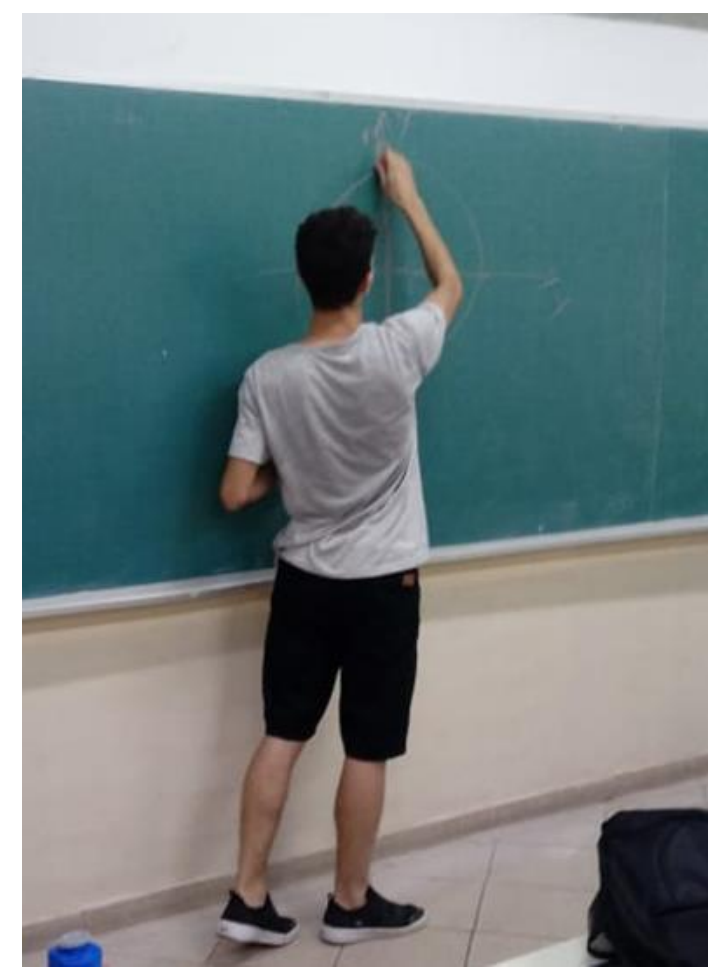

Figura 11. Aluno apresentando sua solução.

Fonte: Dados da Pesquisa.

A ação por parte desse grupo, de apresentar suas resoluções e soluções para a turma foi muito significativa, pois os demais alunos, a partir daquele momento, começaram a questionar e argumentar mais, intensificando as discussões e potencializando, assim, o ensino e a aprendizagem pretendidos.

Etapas 7 e 8 - Em plenária, professores e alunos argumentam, discutem ideias, concepções; busca-se um consenso sobre o processo de resolução:

Assim como as etapas 3, 4 e 5, as etapas 6, 7 e 8 acontecem simultaneamente. Quando um grupo apresenta suas respostas, os outros grupos, mediados pelo professor, apresentam argumentos e, com frequência repensam suas soluções. Nesse momento, o professor, junto com os alunos, busca uma solução coletiva para o problema gerador, no caso: "Qual o valor do seno de $135^{\circ}$ ?" Juntos, muito mais que responder que o seno de $135^{\circ}$ é $\sqrt{2} / 2$, os alunos perceberam que o seno de $135^{\circ}$ tem 


\section{Universidade Federal da Grande Dourados}

o mesmo valor que o seno de 45ํㅡ, não por acaso, mas por entender como esses valores são obtidos no ciclo trigonométrico.

Etapa 9 - Professor formaliza o conteúdo matemático

Com essa etapa "finalizamos" o processo de ensino de funções trigonométricas, pois aqui o professor assume a responsabilidade de detentor do conhecimento deixando de ser apenas mediador. Entendemos que esse processo é imprescindível, pois nesse momento é evidenciado todo o objetivo de realizar a busca pela solução do problema, que é apresentar o novo conteúdo, funções trigonométricas. A Figura 12 apresenta os registros da formalização realizada pelo professor.

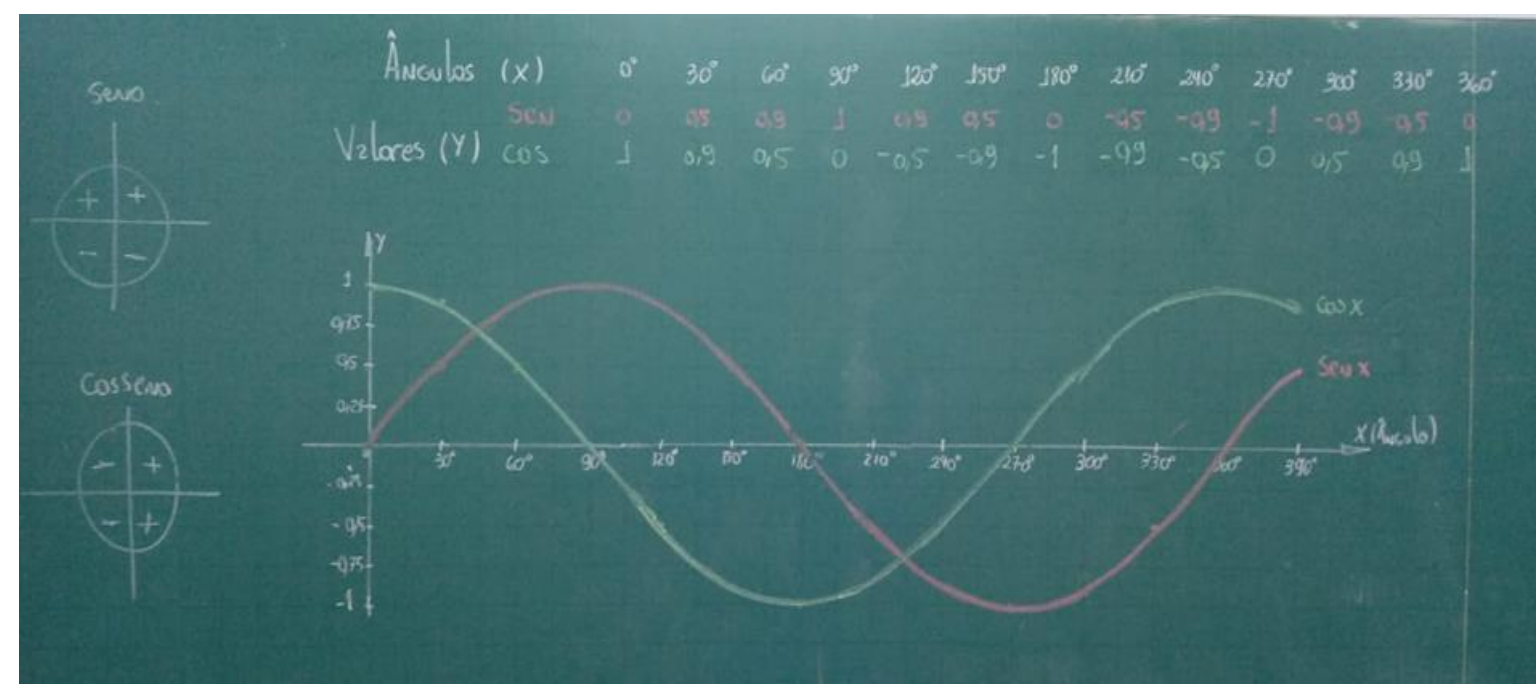

Figura 12. Aluno apresentando sua solução.

Fonte: Dados da Pesquisa.

Utilizando as tabelas construídas pelos alunos e as modificações realizadas na etapa 8 , o professor formaliza o conteúdo matemático de funções trigonométricas, particularmente as funções seno e cosseno.

Etapa 10 - Proposição de novos problemas

Aqui se propõem novos problemas para fixação e ampliação da aprendizagem. Essa etapa pode reiniciar o ciclo do ensino através da Resolução de Problemas; no 


\section{Universidade Federal da Grande Dourados}

caso desta turma, poderíamos buscar responder "porque as funções são expressas em radianos e não em graus?"

E iniciaríamos um novo processo de ensino-aprendizagem através desse novo problema gerador.

\section{CONSIDERAÇÕES FINAIS}

Neste trabalho apresentamos a Metodologia de Ensino-Aprendizagem-Avaliação de Matemática através da Resolução de Problemas, que pode ser realizada na escola e mediada pelo uso de tecnologia. Mais que isso, tivemos a intenção de detalhar todas as etapas dessa metodologia, por acreditar que isso pode favorecer futuras ações de formação de professores que podem utilizar este trabalho como aporte para abordar a Resolução de Problemas.

Vale destacar, ainda, outro aspecto que percebemos é que ao utilizar o GeoGebra no processo de Resolução de Problemas potencializamos aspectos da metodologia, pois os alunos se motivaram mais ao utilizar o software e os processos de generalização, ressignificação e reflexão em torno dos conceitos trabalhados aconteceram com maior velocidade e intensidade.

Finalmente, desejamos que este trabalho seja um suporte para a formação de professores por acreditar que apresentar cada etapa do processo pode facilitar o entendimento dos professores em relação à metodologia, possibilitando, até que eles criem suas próprias e novas etapas. Assim como Serrazina (2017) e Allevato e Onuchic (2014), acreditamos que o trabalho através da Resolução de Problemas apresenta maiores significados para os alunos, pois os encoraja a questionar, experimentar, estimar, explorar e elaborar explicações, que são objetivos de se ensinar e aprender Matemática, na atualidade.

\section{REFERÊNCIAS}


Allevato, Norma. (2014). Ensino-aprendizagem-avaliação de Matemática: por que através da resolução de problemas?. Rio Claro: Seminário em Resolução de Problemas.

Allevato, Norma.; Onuchic, Lourdes. (2014). Ensino-Aprendizagem-Avaliação de Matemática: por que Através da Resolução de Problemas? Jundiaí: Resolução de problemas: teoria e prática. Paco Editorial.

Allevato, Norma.; Onuchic, Lourdes. (2011). Pesquisa em Resolução de Problemas: Caminhos, Avanços e Novas Perspectivas. Rio Claro: Bolema.

Brasil. (2018) Ministério da Educação. Base Nacional Comum Curricular. Brasília: SEMT/MEC.

Brasil. (2017) Ministério da Educação. Base Nacional Comum Curricular: Educação é a base. Brasília: SEMT/MEC.

Brasil. (1998). Secretaria de Educação Fundamental. Parâmetros Curriculares Nacionais para Ensino Fundamental (PCNEF): Matemática. Brasília: SEMT/MEC.

Chang, T., Lee, W., Fu, H., Lin, Y., \& Hsuech, H. (2007). A study of an augmented CPFR model for the 3C retail industry. Supply Chain Management: An International Journal, $\quad$ 200-209. http://dx.doi.org/10.1108/13598540710742518

Costa, Felipe. (2017). O ensino de funções trigonométricas com o uso da modelagem matemática sob a perspectiva da teoria da aprendizagem significativa. São Paulo: Dissertação (Mestrado em Educação Matemática) - Programa de 
Estudos Pós-Graduados em Educação Matemática, Pontifícia Universidade Católica de São Paulo.

Fiorentini, Dario.; Lorenzato, Sergio. (2012). Investigação em educação matemática: percursos teóricos e metodológicos. 3. ed. Campinas: Autores Associados. Goldenberg, Miriam. (2007). A arte de pesquisar. Rio de Janeiro: Record.

Gonçalves, Ricardo.; Allevato, Norma. (2020). Resolução De Problemas como Metodologia de Ensino e Aprendizagem Significativa das Funções Definidas por várias Sentenças. Curitiba: editora CRV.

Lüdke, Menga.; André, Marli. (1986). Pesquisa em educação: abordagens qualitativas. São Paulo: EPU.

Meneghelli, Juliana. (2018). Resolução de problemas e o software Geogebra: um caminho para o ensino das funções trigonométricas seno e cosseno. Blumenau: Universidade Regional de Blumenau - FURB.

Sanches, Isabel. (2005). Compreender, agir, mudar e incluir. Da investigação-acção à educação inclusiva. Lisboa: Revista Lusófona de Educação.

Serrazina, Lurdes. (2017). Resolução de problemas e formação de professores: um olhar sobre a situação de Portugal. In: Onuchic, L. R. et al. (Org.). Perspectivas para resolução de problemas. São Paulo: Livraria da Física.

Van de Walle, John. (2009). Matemática no ensino fundamental: formação de professores e aplicação em sala de aula. Porto Alegre: Artmed.

Vianna, Heraldo. (2007). Pesquisa em educação: a observação. Brasília: Liber Livro. 